\title{
If I Think That I, Myself, am a Fool (369th-384th of Tcheonzamun, the Thousand Character Essay)
}

\author{
Hyeonhi Regina Park ${ }^{1}$, Jiah Anna Kim², Rosa Kim³ ${ }^{3}$ Alain Hamon ${ }^{4}$, Sohwa Therese \\ $\mathrm{Kim}^{5}$, Sangdeog Augustin Kim ${ }^{6 *}$
}

\author{
${ }^{1}$ Department of Elderly care and welfare, Joongbu University Kumsan, Republic of Korea (ROK) \\ ${ }^{2}$ Department d'Expertise economique, Université de Paris-Est Creteil Paris, France \\ ${ }^{3}$ Specialité d'Economie politique, Ecole des Hautes Études en Sciences Sociales (EHESS), Paris, France \\ ${ }^{4}$ Groupe Scolaire iféa-Émilie du Châtelet, 92110 Clichy, France \\ ${ }^{5}$ Specialité de Sciences Sociales, Ecole des Hautes Études en Sciences Sociales (EHESS) Paris France \\ ${ }^{6}$ Korea Water Resources Corporation, ROK
}

\section{*Corresponding Author}

Sangdeog Augustin Kim

\section{Article History}

Received: 11.11 .2020

Accepted: 24.11.2020

Published: 30.11.2020

\begin{abstract}
The researchers translated the poem of 16 characters from $369^{\text {th }}$ to $384^{\text {th }}$ letters. $369-372$. It will be really good for me to do such a splendid thing. It may be favorable if I come in front of the other ones after being a complete man or woman. In front of my students of Department of Companion animal and animal resources science in Joongbu University, of my five children (Sohwa Therese, Rosa, Jiah Anna, Kunjoo Daegeon-Andrea, Jieun Agatha), and of my wife Hyeonhi Regina. But such a condition does not come to me forever. I am always deficient. So I cannot become a complete one, even the time passed up to my death! 373-376 this phrase tells us "I must not abandon the purpose now ( 弗離)! Even though my character and my behavior are not enough good, but I plan to do the thing someday again in order to have a better attitude for the life (造次).” So I must keep the thing, and then, I can proceed to culture my appearance gradually. In this phrase of Tcheonzamun the first part is more important than the last part. It is similar to the Korean language. In Korean language the first part is important. While in Chinese language the last part is important. Tcheonzamun can be understood well in the Korean language style. So it is considered that Tcheonzamun have been written but by ancient Korean people, not by Chinese people. 377-380. It will be very nice and beautiful if I say modestly "I am sorry!" However, if I think that I am a valueless man or such a woman, is it good or not? No, it is not favorable. I must neither think that I is a fool, nor I must blame myself. Such a thing, it is written in the next phrase of 4 letters (381st-384th). 381-384 I am destined to stand as an incomplete man. However, I, Augustin Kim, must not say to me "You cannot become a good man anyway, even though you try hard to attain such a good state! Because it is impossible for you!" Yes, I must always have 'a whispering voice of' hope. In order that I am able to get up from the miserable place (顛沛), I must consider myself 'as a valuable man or as such a woman (匪虧).' And then, I can change from the poor state into the favorable one step by step. To the complete state, even though it cannot be obtained!
\end{abstract}

Keywords: Poem composed of 16 letters, Chinese language, the importance of phrase, Korean language, Tcheonzamun (The thousand character essay), 369th-384 ${ }^{\text {th }}$ of Tcheonzamun.

\section{INTRODUCTION}

This work has been written on Korean language and the writing was published on the internet [1].

\section{MATerials ANd Methods}

The present researchers have utilized the book of Tcheonzamun (The thousand character essay) [2]. The researchers translated the poem of 16 characters from $369^{\text {th }}$ to $384^{\text {th }}$ letters. And the translation was done with the

Copyright $\odot 2020$ The Author(s): This is an open-access article distributed under the terms of the Creative Commons Attribution 4.0 International License (CC BY-NC 4.0) which permits unrestricted use, distribution, and reproduction in any medium for noncommercial use provided the original author and source are credited. 
Chinese dictionary by Heo [3]. The present researchers referred the book of Chung [4]. And the present researchers reported the new thought that the book of Tcheonzamun has been written on the basis of Korean language [5-9].

\section{RESULTS AND DISCUSSION}

The present researchers started the Tcheonzamun (The thousand character essay) translation. The researchers prayed "Lord, help us to interpret this poem of Tcheonzamun! Please hear our prayers, Lord Jesus amen!" The theme of next poem is "If I think that I, myself, am a fool", and the poem is consisted of 16 letters from $369^{\text {th }}$ to $384^{\text {th }}$ of Tcheonzamun.

\section{Number of Tchenzamun (The thousand character essay) Pronunciation of Chinese character in Korean language Chinese character.}

369-372 In Za Eun Tcheug 仁慈隱惻 I have to hide (隱) my grief or sorrow (惻) in front of other person, if I decided to help (慈) others with good things (仁).

It will be really good for me to do such a splendid thing. It may be favorable if I come in front of the other ones after being a complete man or woman. In front of my students of Department of Companion animal and animal resources science in Joongbu University, of my five children (Sohwa Therese, Rosa, Jiah Anna, Kunjoo Daegeon-Andrea, Jieun Agatha), and of my wife Hyeonhi Regina. But such a condition does not come to me forever. I am always deficient. So I cannot become a complete one, even the time passed up to my death!

373-376 Zo Tcha Bul Li 造次弗離 Do not (弗) stop totally (離), it is in order to make the condition better (造) little by little (次).

This phrase tells us "I must not abandon the purpose now (弗離)! Even though my character and my behavior are not enough good, but I plan to do the thing someday again in order to have a better attitude for the life (造次).” So I must keep the thing, and then, I can proceed to culture my appearance gradually.

In this phrase of Tcheonzamun the first part is more important than the last part. It is similar to the Korean language. In Korean language the first part is important. While in Chinese language the last part is important. Tcheonzamun can be understood well in the Korean language style. So it is considered that Tcheonzamun have been written but by ancient Korean people, not by Chinese people.

377-380 Zeol Eui Lyeom Toe 節義廉退. It might be truly good if I say “I made a mistake, and I am sorry! (退)” and if I retire myself in front of other persons (廉). By this retirement, I can keep (節) the just and the rightness (義).

It will be very nice and beautiful if I say modestly "I am sorry!" However, if I think that I am a valueless man or such a woman, is it good or not? No, it is not favorable. I must neither think that I is a fool, nor I must blame myself. Such a thing, it is written in the next phrase of 4 letters (381st-384th).

381-384 Zeon Pae Bi Hyu 顛沛匪虧 I must not think (匪) that I, myself, am a fool (虧), if I want to recover straightly (顛) from the fallen state (沛).

I am destined to stand as an incomplete man. However, I, Augustin Kim, must not say to me "You cannot become a good man anyway, even though you try hard to attain such a good state! Because it is impossible for you!" Yes, I must always have 'a whispering voice of' hope. In order that I am able to get up from the miserable place (顛沛), I must consider myself 'as a valuable man or as such a woman (匪虧).' And then, I can change from the poor state into the favorable one step by step. To the complete state, even though it cannot be obtained!

\section{ACKNOWLEDGEMENTS}

We thank Mr Yeonghag Park and Mrs Hilye Sarah Kim, Mr Ilsoo Joseph Kim and Mrs Bohwa Kim and Ms Jieun Agatha Kim, Father Jean Blanc and Father Hifumi Iwazaki and Father Xavier Ha, Mrs Tamako Hayashi and Mr Yoshihiro Hayashi, Mrs Francine Tenaillon and Professor Nicolas Tenaillon, Mrs Sook Ja Nam and Mrs Sookja Martha Min and Kisoon Cecile Song, Professor Ryosei Kayama and Professor Mitsuaki Ohshima and Professor Shigekata Yoshida, Professor Tae Song Koh and Professor Jae In Yun and Professor Byung Hoon Park and Professor Ik Suk Yun, Father Gangseob Leo Eom OFM and the members of Daejeon Ludovich of Ordo Franciscanus Saecularis, Father 
Jungeob Paul Lee and the members of Daejeon Nae-dong Catholic Church, Groundwater well registering team in Korea

Water Resources Corporation and the student of Joongbu University.

\section{REFERENCES}

1. Park, H.R. \& Kim, S.A. (2016). Naega nareul baborago saenggaghamyeon. (If I think that I, myself, am a fool.). Tch eonzamuneun urigeul ibnida, Zunggug geuli anigoyo. ('The thousand character essay' is written but on a Korean lan guage, not on a Chinese language.) http://cafe.naver.com/angolstar/2727.

2. Kim, J. J. (2002). Hanseogbong Tcheonzamun(Tcheonzamun book written by Mr Hanseogbong). Eunkwang publish ing company. Seoul, 1-52.

3. Heo, L. (1988). Gweoui Leubao Zidian(Chinese language Daily Journal Dictionary) Gweoui Leubao(Chinese langu age Daily Journal) Publishing Company. Taipei, 1-842.

4. Chung, I.B. (2013). Choseonsa Yeonku (Study of Korean History) (Edited by SJ Moon). Korea History Foundation. Seoul. 2:20-959.

5. Park, H.R., Kim, J.A., Kim, K.D.A., Kim, J.A., Kim, S.T., Kim, R., Hamon, A., Tenaillon N., \& Kim, S.A. (2017). Ancient Koreans' petition to God in Tcheonzamun: The thousand character essay poem (641st to 656th letters). Jour nal of Languages and Culture, 8(6): 79-84,

6. Park, H.R. et al. (2017). "Let's make from now on the land of our mind broader! With a hidden meaning of 'We had better stop here completely!'; from “Translation of a Tcheonzamun(The Thousand Character Essay; written of 1000 letters in Chinese character) poem(657th - 672nd letters)." Journal of Languages and Culture, 8(2): 10-13,

7. Park, H.R. et al. (2018). Standing straight with the title, "As this miserable and fungus-like small plant becomes a big and favourite tree' adapted from the Tcheonzamun poem (753rd to 768th). Journal of Languages and Culture, 9(2): 7-12,

8. Park, H.R. et al. (2019). Sensible Love of Maeg Wife (Ibbeungaksi!) (785th - 800th). South Asian Research Journal of Humanities and Social Sciences, 1(2): 83-86.

9. Park, H.R. et al. (2020). Mamma's Diary (929th-944th of Tcheonzamun). South Asian Research Journal of Humanit ies and Social Sciences, 2(5): 433-437. 